\title{
PSYCHOLOGICAL ASSESSMENT IN INDUSTRY
}

\author{
R. P. VAN DER MERWE \\ Department of Industrial and Organisational Psychology \\ University of Port Elizabeth
}

\begin{abstract}
Recent and ongoing developments in the South African labour legislation, and especially the implications of the Employment Equity Act, highlight once again the importance of the validation of instruments to be used for assessment purposes. A needs analysis was done with regard to psychological assessment in industry today. Biographical information on each company is supplied, including the number of employees. The role of psychologi$\mathrm{cal}$ assessment in the selection procedure is discussed, as well as levels at which tests are applied. The different tests used as well as the users are indicated. Comments, recommendations and shortcomings are discussed.
\end{abstract}

\section{OPSOMMING}

Onlangse en voortdurende ontwikkelinge in die Suid-Afrikaanse arbeidswetgewing, en veral die implikasies van die Wet op Gelyke Indiensneming, beklemtoon weer eens die belangrikheid van die geldigheid van instrumente wat gebruik word vir evalueringsdoeleindes. 'n Behoeftebepaling is gedoen met betrekking tot hedendaagse sielkundige evaluering in die bedryf. Biografiese inligting word oor die onderskeie organisasies verstrek, insluitende die aantal werknemers. Die rol van sielkundige evaluering in die keuringsprosedure word bespreek, sowel as die vlakke waarop toetsing toegepas word in die organisasies. Die verskillende toetse wat gebruik word, sowel as die toetsgebruikers, word angedui. Opmerkings, anbevelings en tekortkominge word bespreek.

Psychological tests are commonly employed as aids in occupational decisions, including the selection and classification of human resources. From the assembly-line operator or filing clerk, to top management, there is scarcely a type of job for which some kind of psychological test has not proved helpful in such matters as hiring, job assignment, transfer, promotion, or termination (Anastasi \& Urbina, 1997).

According to Owen and Taljaard (1996) it appears that psychological tests can contribute to the efficiency of selection and placement in industry, if used carefully and responsibly. Friedenberg (1995) refers to research which compared different selection procedures (application forms, letters of reference, interviews, testing) and confirmed that although each technique has its own merits, standardized tests are the most psychometrically sound. The importance of the validation of any instruments to be used for assessment purposes, is highlighted by recent and ongoing developments in the South African labour legislation, and especially the implications of the Employment Equity Act (Eckstein, 1998). These issues also accentuate once again the need for responsible use of tests and other psychological assessment procedures.

In the light of the abovementioned information, it was decided to initiate an investigation into the use of psychological assessment in industry. This study reports the findings of such exploratory research that was undertaken to establish which psychological tests are used, and for what purposes, in industry today.

\section{METHOD}

\section{Sample}

A non-probability convenience sample of five organisations was drawn from the Port Elizabeth and Uitenhage areas of the Eastern Cape. The research can thus be regarded as a qualitative investigation. Background information on the various organisations that were selected, are supplied in Table 1.

Requests for reprints should be addressed to: $R P$ vd Merue, Dept. of Industrial Psycho$\log \gamma$ UPE, PO Box 1600, Port Elizabeth, 6000.
TABLE 1

\section{PARTICIPATING ORGANISATIONS}

\begin{tabular}{|c|l|c|}
\hline $\begin{array}{l}\text { Organi- } \\
\text { sation }\end{array}$ & Type of business & Employees \\
\hline A & $\begin{array}{l}\text { Branch of large insurance company } \\
\text { (nation wide } \pm 13000 \text { employees) }\end{array}$ & 600 \\
\hline B & $\begin{array}{l}\text { Branch of large banking group (nation } \\
\text { wide } \pm 37000 \text { employees) }\end{array}$ & 1300 \\
\hline C & $\begin{array}{l}\text { Government department responsible } \\
\text { for security, law and order }\end{array}$ & 19000 \\
\hline D & $\begin{array}{l}\text { Branch of large beverage company (na- } \\
\text { tion wide } \pm 8000 \text { employees) }\end{array}$ & 1000 \\
\hline E & Motor manufacturing company & 6500 \\
\hline
\end{tabular}

From Table 1 it appears that the participating organisations cover a wide range of different economic activities.

\section{Procedure}

Postgraduate students in Industrial and Organizational Psychology acted as field workers in this study. They - were thoroughly briefed by the researcher on the interviewing procedure to be used for this research. The data was collected by means of individual interviews that these students conducted with a designated representative from the human resource department of each organisation that was involved.

Mostly these representatives were personally responsible for testing in their organisations. Where this was not the case, the representative was the person locally involved with the arrangements and administration regarding testing in that organisation. These people provided the information that was used in this research by discussing the testing policy of their organisation with the interviewers.

\section{Data analysis}

All the data gathered by means of these interviews, were analysed by means of content analysis. Inferences were made on inspection of the data gathered. 


\section{RESULTS}

The results of this research are presented in the following format:

\section{Brief testing policy of the organisation \\ Tests used in the organisation \\ Test users (administrators) in the organisation \\ Comments by test users in the organisation}

Based on the questions asked during the interviews, the following information on each organisation, was made available.

\section{BRIEF TESTING POLICY}

\section{ORGANISATION A}

In the case of organisation A, they make use of a clearly defined selection procedure which includes the following: application blanks, preliminary interviews, psychometric tests, final selection interviews and reference checking. Psychometric tests are merely used as an additional aid in the selection process and are required to be culture-fair and non-discriminatory. Employment equity enjoys a high priority with this organisation.

In this organisation tests are used for selection and management information, and they tend to use it more at the lower levels of employment. At management level they use assessment centres for selection and promotion purposes.

\section{ORGANISATION B}

This organisation uses a clearly stated and defined selection procedure, with different steps. It was recently revised to comply with the latest labour legislation. Their approach is that it is not always equally important to use psychological tests in the selection process. The specific job one is selecting for, will indicate whether it is necessary to do testing or not. Tests are never used on their own - always together with an interview and other input.

Tests are used at all levels in this organisation, for selection, placement, promotion and strategic restructuring. They do not make use of assessment centres because they regard them as too expensive and time consuming.

\section{ORGANISATION C}

Organisation $\mathrm{C}$ makes use of a clearly stated selection procedure in which they include: application forms, reference checking, testing, diagnostic interviewing. Tests are never chosen at random - a thorough job analysis is first conducted to determine the skills that are needed to successfully perform the job.

Tests are used at all levels in this organisation, for selection, placement, training and transfers, but not for promotions. Although they previously made use of assessment centres, these are no longer in use.

\section{ORGANISATION D}

This organisation uses a clearly stated selection procedure and policy, in which they make use of application blanks, preliminary interviews, psychometric assessments, diagnostic interviews and reference checking.

Psychometric assessment is regarded as important in this organisation's selection process. The purpose of psychometric assessment is to provide specialist information in support of managerial decision-making by increasing the accuracy of decisions regarding the selection, promotion and development of employees. The assessments should also assist individual employees in gaining insight into themselves, for the purpose of their own self development.
Tests are used in this organisation for all positions from shopfloor level and above. They are however also used for certain positions where specific psychometric and psychological makeup is deemed necessary (ie apprentices and bursars).

\section{ORGANISATION E}

This organisation makes use of a selection procedure, which includes inter alia interviews. All information gathered during the selection process is used by them to make a final appointment decision. They use tests mainly for selection purposes and it is mostly used at managerial level, although also at a few entry grade levels.

\section{TESTS USED}

In Table 2 the various tests used by the different organisations are indicated. Note that the most tests are used by one organisation only. Some tests are used by two or more organisations, and the most widely used test is the 16PF. which is used by four organisations. For greater clarity, a brief description of the abbreviations used to indicate the different tests, follows after Table 2.

TABLE 2

TESTS USED BY DIFFERENT ORGANISATIONS

\begin{tabular}{|l|c|c|c|c|c|}
\hline & & & & & \\
\hline TESTS: & & & & & \\
\hline 16 PF & $\mathrm{X}$ & $\mathrm{X}$ & $\mathrm{X}$ & & $\mathrm{X}$ \\
\hline SORT & & $\mathrm{X}$ & $\mathrm{X}$ & & \\
\hline TAT & & $\mathrm{X}$ & & & \\
\hline MBTI & $\mathrm{X}$ & & & & \\
\hline MMPI & & & & $\mathrm{X}$ & \\
\hline 19 FII & $\mathrm{X}$ & & & & \\
\hline HL Bat & $\mathrm{X}$ & $\mathrm{X}$ & & & \\
\hline INT Bat & $\mathrm{X}$ & $\mathrm{X}$ & $\mathrm{X}$ & & \\
\hline NORM Bat & & $\mathrm{X}$ & & & \\
\hline SAT & $\mathrm{X}$ & & $\mathrm{X}$ & & \\
\hline AAT & & & $\mathrm{X}$ & & \\
\hline PAB & $\mathrm{X}$ & & & & \\
\hline SAWAIS & & & $\mathrm{X}$ & $\mathrm{X}$ & \\
\hline CPA & & & & $\mathrm{X}$ & \\
\hline DOVER & & & & & $\mathrm{X}$ \\
\hline GI Exerc & & & & & $\mathrm{X}$ \\
\hline Presentation & & & & & $\mathrm{X}$ \\
\hline In-basket & & & & & $\mathrm{X}$ \\
\hline
\end{tabular}

Sixteen Personality Factor Questionnaire (16 PF): It measures 16 primary personality traits and is used inter alia in industry and business in selection, placement and promotion of employees by predicting important job related criteria such as work efficiency, tolerance of routine etc (Huysamen, 1996; Spangenberg, 1990).

Structured-Objective Rorschach Test (SORT): The SORT is based on the traditional Rorschach Test and its aim is to obtain psychologically meaningful data by means of which a broad overall picture of the individual can be obtained (Spangenberg, 1990). Together with data from other tests, this can then be used for counselling, selection and the prediction of job success. 
lity test which is regarded to be especially suited to assessing motivation, such as the need for achievement or affiliation (Huysamen, 1996).

Myers-Briggs Type Indicator (MBTI): This test was designed to implement Jung's theory of type, as understood by the author (Isabel Myers). More specifically the aim is to identify the basic preferences of people with regard to perception and judgement. These preferences are: Extraversion-Introversion, Sensing-Intuition, Thinking-Feeling, and Judgement-Perception (Spangenberg, 1990).

Minnesota Multiphasic Personality Inventory (MMPI): It is a broad-band test designed to assess a number of the major patterns of personality and emotional disorders. To an extent it highlights any signs of pathology in people being tested (Aiken, 1994; Anastasi \& Urbina, 1997).

Nineteen Field Interest Inventory (19 FII): This inventory measures occupational interests with respect to 19 broad fields of activity. It also measures the extent to which a person is actively or passively interested in the 19 fields, as well as the extent to which the interests are work- or hobby-related (Owen \& Taljaard, 1996).

High Level Battery (HL Bat): This battery provides a measurement of general intelligence, arithmetical ability and certain language abilities. It can be used for vocational guidance as well as the selection and classification of high level employees, and is suitable for testees with matric or higher qualifications (Huysamen, 1996; Owen \& Taljaard, 1996; Spangenberg, 1990).

Intermediate Battery (INT Bat): This battery was designed to measure certain mental abilities, including mental alertness, arithmetical ability, some aspects of language, and clerical skills. It can be used in vocational guidance as well as for the selection of persons who have received not more than 12 years of schooling (Huysamen, 1996; Owen \& Taljaard, 1996; Spangenberg, 1990).

Normal Battery (NORM Bat): This battery was designed to measure a number of mental abilities, including mental alertness, computation and certain language skills. It can be used in vocational guidance as well as for the selection of persons with 9 to 10 years of schooling (Huysamen, 1996; Owen \& Taljaard, 1996; Spangenberg, 1990).

Senior Aptitude Tests (SAT): This test was designed to measure a number of aptitudes and the results can be used for vocational guidance and selection purposes (Huysamen, 1996; Owen \& Taljaard, 1996).

Academic Aptitude Test (AAT): The aim of this test is to serve as an aid in the guidance of senior pupils with regard to subject and career choice. More specifically, it provides an assessment of general intellectual ability, verbal ability, mathematical ability and spatial ability. It may also be of value in selection and placement decisions (Spangenberg, 1990).

Programmer Aptitude Battery (PAB): This battery measures aptitude for computer programming. It is intended to be used on individuals who have little or no experience in computer programming, although it might be useful in selecting existing programmers. It should not be used on persons who have not passed matric (Owen \& Taljaard, 1996).

South African Wechsler Adult Intelligence Scale (SAWAIS): This test is a verbally administered individual scale that was designed to evaluate the intellectual functioning of the older child and adult (Huysamen, 1996; Spangenberg, 1990).

Career Path Appreciation (CPA): This is based on a stratified systems theory and assesses a manager's ability to deal with challenges of varying complexity. Judgement to make decisions in various conditions of uncertainty is assessed along with the ability to adopt long-term and short-term thinking. This evaluation works on a semi-structured interview system.

Dover/Vienna Test System (DOVER): This is a machine with lights of different colours and the testee is expected to coordinate the hand switches with the different lights of the machine as they come on and off. The performance of the candidate is scored automatically. Performance under stress, orientation ability, levels of productivity, and learning ability, are some of the aspects evaluated by this system.

Group Interaction Exercise (GI Exerc): This can be regarded as a group problem solving exercise. The group of candidates is given a problem to discuss and within fifteen minutes they must come to a solution. Afterwards each member of the group's contribution is evaluated and considered to determine if it contributed to the final outcome reached by the group.

Presentation: This exercise is similar to the previous (group interaction exercise) except that the candidate works as an individual. The candidate is given a problem and allowed five minutes to think about a way of solving it. Then the candidate has to make an oral presentation debating and demonstrating how the problem can best be solved.

In-basket Exercise: This exercise consists of samples of typical items or activities found in the department in which the vacancy exists. Candidates are asked to indicate what action should be taken with regard to each item or activity. In other words, it is a type of simulation exercise in which the person must deal with a pile of paperwork - letters, reports, phone messages, and so on - typical of what might be found in a manager's in-basket.

\section{TEST USERS (ADMINISTRATORS)}

In Table 3 the various persons responsible for testing in the different organisations, are indicated. Note that these are the test users and that they are not necessarily the same people as the representatives who provided the information on each organisation.

TABLE 3

\section{TEST USERS IN DIFFERENT ORGANISATIONS}

\begin{tabular}{|c|l|}
\hline $\begin{array}{c}\text { Organi- } \\
\text { sation }\end{array}$ & Test user \\
\hline A & $\begin{array}{l}\text { Psychometrists or psychologists. Special manager at } \\
\text { head office overall responsible for testing in company } \\
\text { and sees to correct procedures and standards of testing. }\end{array}$ \\
\hline B & Psychometrist or psychologist. \\
\hline C & Psychometrist or psychologist. \\
\hline D & $\begin{array}{l}\text { Use external consulting psychologists. Consulting psy- } \\
\text { chologist available at head-office. }\end{array}$ \\
\hline E & $\begin{array}{l}\text { No qualified test user. Interpretation done by external } \\
\text { consulting psychologists. }\end{array}$ \\
\hline
\end{tabular}

From Table 3 it appears that most of the organisations have their own psychometrists or psychologists. The others make use of consulting psychologists.

\section{COMMENTS BY ORGANISATIONAL REPRESENTATIVES}

In organisation $\mathbf{A}$ they are satisfied with the tests they are using in some areas, and in other areas they are less satisfied. Tests are however useful for the identification of potential in individuals whose scholastic background is not up to standard. Presently they are looking at the validity of the tests used and they are attempting to implement more culture-fair tests. 
According to the feedback from organisation $\mathbf{B}$, a test is only as good as the person that uses it. They feel strongly that tests must be used in the right way, and also that we still have a long way to go to get to culturally fair tests.

In general, organisation $\mathrm{C}$ is satisfied with the tests that are being used by them. As long as the tests are used for the purpose for which they were intended, they are seen to be a useful aid. Many of the tests used are however outdated in some instances, and should be updated. Because they question the culture-fairness of the tests used, industrial psychologists at their head office have standardized most of the tests on the organisation's population, with resulting norms for different culture groups. Due to the issues with regard to culture-fairness, they no longer use psychometric tests for promotion of employees (to evaluate leadership potential). They now make use of a method called Targeted Selection (also known as the assessment interview).

In the case of organisation $\mathbf{D}$ there is the feeling that possibly they sometimes put too much emphasis on test results. To improve the level of interpretation of results, test results and work performance results are frequently correlated at their head office. They are very committed to culture-fairness in their testing - the reason why they removed the $16 \mathrm{PF}$ from their batteries of tests.

In organisation $\mathbf{E}$ it is felt that they are generally satisfied with the tests they are using because these proved to test what they purport to test. They however question the culture-fairness of the $16 \mathrm{PF}$.

\section{DISCUSSION AND RECOMMENDATIONS}

A selection procedure may be fairly simple or very complex, depending on the nature of the organisation, the task for which individuals are being selected, and the philosophy of the human resource management (Aiken, 1994). Psychological tests can be of great value in employee selection because of their objectivity and validity (Schultz \& Schultz, 1998). It must however be regarded as an aid in the selection process - never to be used on its own, or to replace the selection procedure.

From this investigation into psychological assessment in practice, it appears that psychological tests are not used on their own in industry. As an additional aid which is used in decision making, it normally forms part of a defined procedure which includes different, interrelated, specific steps.

Psychological tests are not only used for selection purposes, but also for placement, promotion, transfers, training and development. Furthermore, it appears that these tests are often used at different levels in the organisations which participated in this study.

The tests that are used by these organisations (see Table 2), are mainly South African adjusted and validated material, distributed by the Human Sciences Research Council. Most test administrators of these organisations (see Table 3) are trained and qualified test users who are well aware of the laws and rules that are governing psychological testing in South Africa. To conform to these regulations, some of the organisations make use of the services of external consulting psychologists. The researcher therefore concludes that psychological assessment is conducted at a professional level in the organisations surveyed.

From comments by the organisation representatives interviewed in this investigation, it appears that they are satisfied with the tests they are using. They also stressed the point that test users must be well trained and tests must be used for the purpose for which they were intended. Mention was made that certain of the tests and test material being used, were outdated.

According to Huysamen (1996), one of the major stumbling blocks regarding the use of psychological tests in South Africa stems from the complexity of creating tests which may be used across a diversity of linguistic and cultural backgrounds. Of major concern are the implications of possible discrimination and therefore many of these organisations are presently working towards the validation of tests in their own work environments. Definite needs for culture-fair tests were frequently expressed by the representatives of the organisations involved in this initial investigation.

In this regard it is interesting to note that the $16 \mathrm{PF}$ is the one test used by most of these organisations. It is used by all organisations except for one (organisation D) - who recently removed it from their batteries of tests because they found it not to be culture-fair. Another organisation (organisation E) is still using it, but also questions the culture-fairness of the $16 \mathrm{PF}$.

In evaluating the findings of this study, one has to bear in mind that this was initial, superficial, exploratory research, which involved a very small sample. Nevertheless, the findings are indicative of the typical issues that South African organisations are faced with when implementing psychological assessment today, and therefore cannot completely be disregarded.

It seems to be a sensible suggestion that test manuals and other test material (also norms) should be updated more frequently by the distributor of a test. Consideration should also be given to the development of new tests, with special emphasis on culture-fairness - which could possibly be enhanced by implementing competency based assessment, as it is job related rather than norm based.

Presently it is very important that tests must be validated for the different organisations in which they are used. This also implies that in each organisation, for each specific job, the validity of the test battery being used, must be ensured. Once again this is something which could possibly be enhanced by also making use of competency based assessment, which is directly linked to job content and inherent job requirements. One must however bear in mind that there are psychological factors which competency measures cannot provide, such as that of learning or developmental potential.

Although this study was a qualitative investigation, it was not possible to always obtain all the detailed information normally required in this type of study. The reason for this is that organisations often regard some psychometric information as confidential. With regard to follow-up research, an expansion of the sample is strongly recommended. This would also lead to a more in depth study of the entire field of psychological assessment in industry.

Lastly, the cooperation of everybody involved in this study, as well as all participating organisations, is greatly appreciated.

\section{REFERENCES}

Aiken, L.R. (1994). Psychological testing and assessment. (8th Ed). Massachusetts: Allyn \& Bacon.

Anastasi, A. \& Urbina, S. (1997). Psychological testing. (7th Ed). New Jersey: Prentice-Hall Inc.

Eckstein, S. (1998). Testing Times. People Dynamics, 17(6): 5455.

Friedenberg, L. (1995). Psychological testing: Design, analysis, and use. Massachusetts: Allyn \& Bacon.

Huysamen, G.K. (1996). Psychological measurement. An introduction with South African examples. Pretoria: J.L. van Schaik.

Owen, K. \& Taljaard, J.J. (1996). Handbook for the use of psychological and scholastic tests of the HSRC. Pretoria: HSRC.

Schultz, D.P. \& Schultz, S.E. (1998). Psychology and work today. (7th Ed). New Jersey: Prentice-Hall Inc.

Spangenberg, H. (1990). Assessing managerial competence. Cape Town: Juta. 